\title{
Antioxidant and antigenotoxic effect of dairy products supplemented with red ginseng extract
}

\author{
Hanyeong Park, ${ }^{*}$ Minhee Lee, ${ }^{*}$ Kee-Tae Kim, $†$ Eunju Park, ${ }^{* 1}$ and Hyun-Dong Paik $\$ \ddagger^{1}$ \\ *Department of Food and Nutrition, Kyungnam University, Changwon, 51767, South Korea \\ †Bio/Molecular Informatics Center, Konkuk University, Seoul, 05029, South Korea \\ †Department of Food Science and Biotechnology of Animal Resources, Konkuk University, Seoul, 05029, South Korea
}

\section{ABSTRACT}

The purpose of this study was to evaluate the antioxidant and antigenotoxic effect of dairy products milk $(\mathrm{M})$ and yogurt (Y) after the addition of $2 \%$ red ginseng extract to milk (RM) and to yogurt (RY). Total phenolic content, total flavonoid content, 2,2-diphenyl1-picrylhydrazyl radical scavenging activity, oxygen radical absorbance capacity, and total radical trapping antioxidant potential were determined in the samples. Furthermore, antigenotoxic effect of samples was measured, using comet assay in human leukocytes. Total phenolic content and total flavonoid content of RM $[38.3 \pm 0.8 \mathrm{mg}$ of gallic acid equivalents (GAE)/100 $\mathrm{g}, 23.6 \pm 0.1 \mathrm{mg}$ of quercetin equivalents $(\mathrm{QE}) / 100 \mathrm{~g}]$ and RY $(41.1 \pm 0.9 \mathrm{mg}$ of GAE/100 g, $18.7 \pm 0.1 \mathrm{mg}$ of $\mathrm{QE} / 100 \mathrm{~g})$, respectively, were higher than those of $\mathrm{M}$ $(6.31 \pm 0.2 \mathrm{mg}$ of GAE/100 g, $10.4 \pm 0.1 \mathrm{mg}$ of QE/100 $\mathrm{g})$ and $\mathrm{Y}(8.1 \pm 0.9 \mathrm{mg}$ of GAE/100 g, $8.4 \pm 0.2 \mathrm{mg}$ of $\mathrm{QE} / 100 \mathrm{~g})$, respectively. The 2,2-diphenyl-1-picrylhydrazyl radical scavenging activity and oxygen radical absorbance capacity values increased significantly after the addition of $2 \%$ red ginseng in both. Additionally, the total radical trapping antioxidant potential in RM $(787.7 \pm 7.0 \mu \mathrm{g} / \mathrm{mL})$ was lower than in $\mathrm{M}(2074.0 \pm$ $28.4 \mu \mathrm{g} / \mathrm{mL}$ ). The $\mathrm{H}_{2} \mathrm{O}_{2}$-induced DNA damage in $\mathrm{RY}$ $(0.1 \pm 0.0 \mathrm{mg} / \mathrm{mL})$ was less than the damage in $\mathrm{Y}(0.4$ $\pm 0.0 \mathrm{mg} / \mathrm{mL}$ ), but we found no significant difference between M and RM. This study indicates that supplementation with red ginseng can fortify the antioxidant and antigenotoxic effects of dairy products effectively.

Key words: dairy product, red ginseng, antigenotoxic effect, flavonoid

\footnotetext{
Received March 5, 2018.

Accepted June 14, 2018.

${ }^{1}$ Corresponding authors: hdpaik@konkuk.ac.kr and pej@kyungnam .ac.kr
}

\section{INTRODUCTION}

Functional foods have been defined as foods that provide an additional physiological benefit that may prevent disease or promote health and wellbeing (Joseph, et al., 2018; Li et al., 2018). Many products, such as milk supplemented with vitamins, CLA, or omega-3, in addition to yogurt and dairy beverages enriched with probiotics, are now available in the market. These products are considered functional dairy products (Mattila-Sandholm and Saarela, 2005). The health benefits of milk have been known for a long time. In particular, beyond the presence of valuable nutrients, milk also contains antioxidant factors. Many researchers (Songisepp et al., 2004; Liu et al., 2005; Aloğlu and Öner, 2011) reported the antioxidant effects of dairy products such as milk, yogurt, cheese, and kefir. It has been known that dairy products contain CLA, $\alpha$-linolenic acids, $\alpha$-tocopherol, and carotenoids antioxidants (Butler et al., 2008). Some studies showed that antioxidative effects for health benefit occur as a result of the complexation reaction between phenolic compounds and milk proteins after ingestion (Abd El-Maksoud et al., 2018; Lorenz et al., 2007). Phenols and polyphenolics are bioactive compounds as antioxidants that can be dissolved easily in milk. Generally, the use of plant extracts as natural and safe sources of phenols and polyphenols is preferred (Gad and ElSalam, 2010). New types of milk-based beverages are being introduced into the market with natural flavorings, such as chocolate, various herbs, and fruits. Such products contain plant polyphenols such as rutin from fruits and (-)-epigallocatechin gallate from tea, which are known mainly as antioxidants in lipid oxidation (Becker et al., 2004; Habtemariam and Belai, 2018). Dairy products containing n-3 (omega-3), phytosterols, isoflavins, CLA, minerals, and vitamins also play an important role in the development of functional foods. Dairy-based beverages with biofunctional activities are being offered increasingly all over the world, although the dairy-based beverage market is still a niche market 
compared with the sales of regular yogurt and plain milk (Eom et al., 2017a,b).

Red ginseng is made via steaming and drying fresh ginseng, prompting a chemical transformation via heat (Liu et al., 2016). During the steaming process, ginseng starch is gelatinized, causing an increase in saponin content. Traditionally, red ginseng has been used to refresh and enhance human wellbeing, and has been often referred to as an "adaptogenic" (Coon and Ernst, 2002). Korean red ginseng (Ginseng Radix Rubra) has several pharmacological and physiological effects that are being gradually discovered. In particular, the saponin fraction of Korean red ginseng shows a variety of effects, such as anticancer, antihypertension, antidiabetes, antinociception, and improving weak body condition effects (Jung and Jin, 1996). In addition, red ginseng protected smokers from oxidative damage and reduced cancer risk associated with smoking (Jiang et al., 2017).

Therefore, the aim of our investigation was to evaluate the antioxidant and antigenotoxic effect of dairy products supplemented with red ginseng in vitro as compared with regular dairy products. Our hypothesis was that the products supplemented with red ginseng extract may have higher antioxidant and antigenotoxic effect than nonsupplemented ones, and the results from our study can be applied for the functional dairy food industry.

\section{MATERIALS AND METHODS}

\section{Milk and Yogurt Ingredients}

Whole milk (protein $=3 \%$, fat $=4 \%$, TS $=; 12 \%$ ) and skim milk powder (protein $=34 \%$, fat $=0.5 \%$, TS $=95 \%$ ) were purchased from Seoul Milk Co. (Seoul, Korea). Red ginseng extract (solid contents $=62 \pm$ $1.5 \%$, wt/vol) was purchased from Fine Korea Co. (Seoul, Korea). Commercial starter culture (ABT-L yogurt starter culture; Culture Systems, Inc., Mishawaka, IN) was obtained from Samik Dairy and Food Co., Ltd. (Gimje-si, Jeollabuk-do, Korea). Low methoxy (LM) pectin powder from citrus was purchased from Daejung Chemicals and Metals Co., Ltd. (Siheung-si, Gyonggido, Korea).

\section{Preparation of Supplemented Milk and Yogurt Samples}

Supplemented milk was produced by adding $(2 \%$, wt/vol) red ginseng extract. City milk and red ginseng extract was mixed together at $25^{\circ} \mathrm{C}$ with a blender (GMFC-670, Hanil Co., Seoul, Korea) and refrigerated at $4^{\circ} \mathrm{C}$.
Supplemented yogurt was produced by adding $2 \%$ red ginseng extract. The market milk was mixed with skim milk powder and red ginseng extract and was pasteurized at $90^{\circ} \mathrm{C}$ in a water bath (SBC-24, EYELA, Tokyo, Japan) for $10 \mathrm{~min}$. Pasteurized milk was cooled to $37^{\circ} \mathrm{C}$ in a water bath before being inoculated with yogurt starter culture containing Lactobacillus acidophilus, Bifidobacterium longum, and Streptococcus thermophilus. Inoculated milk samples (initial cell concentration = $10^{4} \mathrm{cfu} / \mathrm{mL}$ ) were incubated until its $\mathrm{pH}$ reached 4.4 to 4.5 and stored in refrigerator $\left(4^{\circ} \mathrm{C}\right)$ for overnight. We abbreviated samples of milk, red ginseng extract-supplemented milk, yogurt, and red ginseng-supplemented yogurt as $\mathbf{M}, \mathbf{R M}, \mathbf{Y}$, and $\mathbf{R Y}$, respectively.

\section{Preparations for Determination of Antioxidant Activity}

Four types of liquid samples were diluted 2 fold with $99.5 \%$ methanol and heated at $30^{\circ} \mathrm{C}$ for $1 \mathrm{~h}$ in a water bath. Samples were centrifuged at $2,100 \times g$ for 30 min at $4^{\circ} \mathrm{C}$ and were filtered through filter papers (Whatman No. 1; GE Healthcare Co. Ltd., Chicago, IL). The solvent was removed using a rotary evaporator (N-1000V, EYELA), and the samples were freeze-dried and stored at $-20^{\circ} \mathrm{C}$ until use.

\section{Analysis of Phenolic and Flavonoid Contents of the Extracts}

Total phenolic content was determined according to the method of Folin and Denis (1912). The M, RM, $\mathrm{Y}$, and RY extracts were dissolved in distilled water at a concentration of $100 \mathrm{mg} / \mathrm{mL}$. A sample diluted 2 fold was mixed with $0.4 \mathrm{~mL}$ of Folin-Ciocalteu reagent (Sigma-Aldrich, St. Louis, MO), after which the mixture was allowed to stand at $25^{\circ} \mathrm{C}$ for $3 \mathrm{~min}$. Subsequently, $0.4 \mathrm{~mL}$ of $2 \% \mathrm{Na}_{2} \mathrm{CO}_{3}$ was added to the mixture. The absorbance was measured with an ELISA reader (Sunrise, Tecan Co. Ltd., Grödig, Austria) at $690 \mathrm{~nm}$ after letting the mixture stand for $1 \mathrm{~h}$. The measurement was compared with a standard curve of prepared gallic acid solution and was expressed in the form of milligrams of gallic acid equivalents (GAE) per gram for the triplicate extracts.

Additionally, the total flavonoid content was determined in all the samples using the colorimetric Davis method (Davis, 1947). In this method, extracts reacting with diethylene glycol in alkaline solution produce a yellow chalcone, which is measured at a wavelength of $420 \mathrm{~nm}$. The measurement was compared with a standard curve of prepared quercetin solution and was expressed in the form of milligrams of quercetin equivalents (QE) per gram for the triplicate extracts. 


\section{DPPH Assay}

A solution of $0.8 \mathrm{~mL}$ of $0.2 \mathrm{~m} M$ 1,1-diphenyl-2-picrylhydrazyl (DPPH) in ethanol was added to $0.2 \mathrm{~mL}$ of each sample at different concentrations (100-5,000 $\mu \mathrm{g} /$ $\mathrm{mL}$ ). The test tubes were vortexed and incubated for 10 min at $25^{\circ} \mathrm{C}$ in the dark, and then the absorbance (Abs) values were determined at $492 \mathrm{~nm}$ in an ELISA reader (Sunrise, Tecan Co. Ltd.). The radical scavenging activity (RSA) was assessed by the formula

$$
\operatorname{RSA}(\%)=\left(1-\mathrm{Abs}_{\text {sample }} / \mathrm{Abs}_{\text {blank }}\right) \times 100 .
$$

Ethanol $(0.8 \mathrm{~mL})$ added to each sample solution (0.2 $\mathrm{mL})$ was used as a blank. DPPH solution $(0.8 \mathrm{~mL})$ with the added ethanol $(0.2 \mathrm{~mL})$ was used as a control.

\section{Oxygen Radical Absorbance Capacity Assay}

Antioxidant activities of M, RM, Y, and RY extracts in different concentrations between 250 and $1000 \mu \mathrm{g} /$ $\mathrm{mL}$ were examined for their peroxyl and hydroxyl radical scavenging capacities, using the oxygen radical absorbance capacity (ORAC) assay system. The FLUOstar OPTIMA microplate fluorescence reader (BMG Labtech, Offenburg, Germany) was used with an excitation wavelength of $485 \mathrm{~nm}$ and an emission wavelength of $520 \mathrm{~nm}$. In the final assay mixture, fluorescein $(40 \mathrm{n} M)$ was used as a target of free radical attack with either 2,2'-azobis (2-amidinopropane) dihydrochloride (AAPH; $20 \mathrm{mM}$ ) as a peroxyl radical generator in peroxyl radical scavenging capacity $\left(\mathrm{ORAC}_{\mathrm{RoO}}\right.$ ) assay. Trolox $(1 \mu M)$ was prepared fresh daily and used as a control standard. The analyzer was programmed to record the fluorescence of fluorescein every $2 \mathrm{~min}$ after AAPH was added. All fluorescence measurements were expressed relative to the initial reading. Final results were calculated based on the difference in the area under the fluorescence decay curve between the blank and each sample. All data were expressed as micromoles of Trolox equivalents (TE). One ORAC unit is equivalent to the net protection area provided by $1 \mu M$ Trolox.

\section{Total Radical Trapping Antioxidant Potential}

Total radical trapping antioxidant potential (TRAP) was measured, using a modified version of the photometric method described by Rice-Evans and Miller (1994). The method for measuring antioxidant activity is based on the antioxidant inhibition of the absorbance of the radical cation of 2, 2'-azinobis (3-ethylbenzothiazoline 6-sulfonate) $\left(\mathbf{A B T S}^{\bullet+}\right)$. The $\mathrm{ABTS}^{\bullet+}$ radical cation was formed through the interaction of $\mathrm{ABTS}^{\bullet+}$
$(150 \mu M)$ with the ferryl myoglobin radical species generated by the activation of metmyoglobin $(2.5 \mathrm{mM})$ with $\mathrm{H}_{2} \mathrm{O}_{2}(75 \mu M)$. Twenty microliters of each sample $(250-1,000 \mu \mathrm{g} / \mathrm{mL})$ was added to a tube containing 748 $\mu \mathrm{L}$ of PBS, $32 \mu \mathrm{L}$ of metmyoglobin, and $450 \mu \mathrm{L}$ of ABTS. The tubes were then mixed by vortexing. To prepare a standard curve, $10 \mu \mathrm{L}$ of Trolox standards $(0.5-2.5 \mathrm{mM}), 758 \mu \mathrm{L}$ of PBS, $32 \mu \mathrm{L}$ of metmyoglobin, and $450 \mu \mathrm{L}$ of ABTS were used. The reaction was started by adding $250 \mu \mathrm{L}$ of $\mathrm{H}_{2} \mathrm{O}_{2}$, and absorbance was measured at $734 \mathrm{~nm}$ using a spectrophotometer (UV1601; Shimadzu, Tokyo, Japan).

\section{Cell Culture and Treatments}

We purchased HepG2 cells from the American Type Culture Collection (ATCC, Rockville, MD). The cells were maintained in Dulbecco's modified Eagle's medium (Welgene Inc., Seoul, Korea) supplemented with $10 \%$ heat-inactivated fetal bovine serum, penicillin (100 $\mathrm{U} / \mathrm{mL})$, streptomycin $(100 \mu \mathrm{g} / \mathrm{mL})$, and $2 \mathrm{mg} / \mathrm{mL}$ of $\mathrm{NaHCO}_{3}$ in a humidified $37^{\circ} \mathrm{C}$ incubator gassed with $5 \% \mathrm{CO}_{2}$. The M, RM, Y, and RY extracts were dissolved in dimethyl sulfoxide (DMSO) and added to the culture medium so that the final concentration of DMSO was less than $1 \%$.

\section{Intracellular Reactive Oxygen Species Measurement with Dichlorofluorescein-Diacetate Assay}

Cellular oxidative stress resulting from reactive oxygen species (ROS) generated by $2,2^{\prime}$-AAPH was measured fluorometrically, using the dichlorofluorescein-diacetate (DCFH-DA) method. The DCFH-DA diffuses through the cell membrane and is enzymatically hydrolyzed by intracellular esterase to the non-fluorescent DCFH, which can be rapidly oxidized to the highly fluorescent dichlorofluorescein in the presence of ROS. First, HepG2 cells were cultured in 96-well plates $(5 \times$ $10^{5}$ cells $/ \mathrm{mL}$ ) for $24 \mathrm{~h}$. After the cells were incubated with M, RM, Y, and RY extracts at different concentrations for $30 \mathrm{~min}$, the medium was discarded and the wells were gently washed twice with PBS. Hanks' balanced salt solution (Sigma-Aldrich Chemicals, Poole, UK), which is stable to fluorescence, was added to each well. The AAPH was used to induce peroxyl-radical oxidative stress. After wells were treated with $80 \mu M$ AAPH for 30 min, DCFH-DA was added to the culture plates at a final concentration of $40 \mu M$, and the plates were incubated in the dark for $30 \mathrm{~min}$ at $37^{\circ} \mathrm{C}$. Dichlorofluorescein fluorescence intensity was measured at an excitation wavelength of $485 \mathrm{~nm}$ and an emission 
wavelength of $535 \mathrm{~nm}$ using the FLUOstar OPTIMA microplate fluorescence reader.

\section{Preparation of Human Leukocytes for Comet Assay}

Peripheral venous blood was collected in heparinized vials from 3 healthy male donors with no history of smoking, drinking, or chronic use of medication. Blood samples were centrifuged at $250 \times g$ for $5 \mathrm{~min}$ at $4^{\circ} \mathrm{C}$, and then leukocytes were isolated from the fraction of mononuclear cells containing leukocytes and monocytes via gradient centrifugation (Histopaque 1077, Sigma Chemical Co., St. Louis, MO). Isolated leukocytes were used for the comet assay after being washed with $1 \mathrm{~mL}$ of PBS.

\section{Treatment of Human Leukocytes and Stimulation with Oxidative Stress}

Leukocytes were incubated with M, RM, Y, and RY extracts, which were dissolved in distilled water, and the final concentration was adjusted to $1,5,10$, and $50 \mu \mathrm{g} / \mathrm{mL}$, respectively, in a dark incubator for $30 \mathrm{~min}$ at $37^{\circ} \mathrm{C}$. For oxidative stimulus, they were resuspended in PBS with $200 \mu M \mathrm{H}_{2} \mathrm{O}_{2}$ for 5 min on ice. After each treatment, leukocytes were centrifuged at 1,000 $\times g$ at $4^{\circ} \mathrm{C}$ for $5 \mathrm{~min}$ and washed with PBS. We used $1 \%$ DMSO without oxidative stimulus as the negative control (NC).

\section{DNA Damage Determination via Alkaline Comet Assay}

The antigenotoxic effects of M, RM, Y, and RY extracts on human leukocytes were measured using the alkaline comet assay. Following the treatment, the leukocytes were mixed with $75 \mu \mathrm{L}$ of $0.7 \%$ low-melting agarose. We then added this to slides precoated with $0.7 \%$ agarose. The slides were then immersed in lysis solution (2.5 $M \mathrm{NaCl}, 100 \mathrm{~m} M$ EDTA, $10 \mathrm{~m} M$ Tris, $1 \%$ sodium lauryl sarcosine mixture; subsequently, $1 \%$ Triton X-100 (Sigma Chemical Co.) and 10\% DMSO mixture) for $1 \mathrm{~h}$ at $4^{\circ} \mathrm{C}$. Thereafter, slides were placed into an electrophoresis tank containing $300 \mathrm{~m} M \mathrm{NaOH}$ and $10 \mathrm{mM} \mathrm{Na} 2 \mathrm{EDTA}$ ( $\mathrm{pH} 13.0$ ) for $20 \mathrm{~min}$. An electric current of $25 \mathrm{~V} / 300 \pm 3 \mathrm{~mA}$ was applied for $20 \mathrm{~min}$ at $4^{\circ} \mathrm{C}$ for DNA electrophoresis. The slides were washed 3 times with a neutralizing buffer ( $0.4 M$ Tris buffer, $\mathrm{pH}$ 7.5) for $5 \mathrm{~min}$ at $4^{\circ} \mathrm{C}$ and treated with ethanol for another $5 \mathrm{~min}$. We evaluated the results using image analysis (Komet version 5.0, Kinetic Imaging, Liverpool, UK) and fluorescence microscopy (Leica DMLB, Bensheim, Germany) after staining the slides with 50 $\mu \mathrm{L}$ of ethidium bromide $(20 \mu \mathrm{g} / \mathrm{mL})$, and determined the percentage of fluorescence in the tail (tail intensity; 50 cells from each of 2 replicate slides).

\section{Statistical Analysis}

Statistical analysis was performed using SPSS version 18.0 (SPSS Inc., Chicago, IL). The data were subjected to 1-way ANOVA to determine the differences of samples. Significant differences were compared using the Tukey test at the level of $P<0.05$.

\section{RESULTS AND DISCUSSION}

The aim of our study was to evaluate the ability of dairy products supplemented with and without red ginseng to act as antioxidants and antigenotoxic material. We conducted DPPH RSA, ORAC, TRAP, and cellular antioxidant capacity assays. The antigenotoxic ability of dairy products supplemented with and without red ginseng was estimated using a comet assay, which is a simple and sensitive technique for finding DNA damage.

\section{Total Phenolics and Flavonoid Content}

Phenolic compounds are good sources of natural antioxidants and are the products of secondary metabolism in plants. Their role is important in preventing chronic diseases such as chronic vascular disease, cancer, inflammatory bowel syndrome, and Alzheimer's disease. Flavonoids have powerful antioxidant activities in vitro and are able to scavenge a wide range of reactive oxygen, nitrogen, and chlorine species, such as superoxide, hydroxyl radical, peroxyl radicals (Pannala et al., 1997; Boersma et al., 1999). The total phenolic and total flavonoid contents of M, RM, Y, and RY extracts are presented in Table 1. These results showed that RY had the highest total polyphenol content (TPC; $41.1 \pm 0.9 \mathrm{mg}$ of $\mathrm{GAE} / 100 \mathrm{~g})$, followed by RM, Y, and $\mathrm{M}(38.3 \pm 0.8,8.1 \pm 0.9$, and $6.3 \pm 0.2 \mathrm{mg}$ of GAE/100 g, respectively). Based on our results, RM had the highest total flavonoid content (TFC; 23.6 $\pm 0.1 \mathrm{mg}$ of GAE $/ 100 \mathrm{~g}$ ), followed by RY, M, and Y $(18.7 \pm 0.1,10.4 \pm 0.1$, and $8.4 \pm 0.2 \mathrm{mg}$ of $\mathrm{GAE} / 100$ $\mathrm{g}$, respectively). The TPC and TFC of RM and RY were statistically higher $(P<0.01)$ than those in $\mathrm{M}$ and Y. Supplementing the samples with red ginseng had a significant effect $(P<0.01)$ on the TPC and TFC in $\mathrm{M}$ and $\mathrm{Y}$. The interaction between polyphenol and protein was affected by (1) the form of polyphenol, (2) projection of phenolic hydroxyl groups, addition of galloyl groups, and (3) position of peripheral groups imposed by the stereochemistry of the pyranic ring of the polyphenol molecule (Kawamoto et al., 1995, 1996; 
Table 1. Total phenol content (TPC) and total flavonoid content (TFC) of red ginseng extract and M, RM, Y, and RY samples at $100 \mathrm{mg} / \mathrm{mL}$

\begin{tabular}{|c|c|c|c|c|c|}
\hline Item & \multicolumn{5}{|c|}{ Sample $^{1}$} \\
\hline $\begin{array}{l}\text { TPC }\left(\mathrm{mg} \text { of } \mathrm{GAE}^{2} / 100 \mathrm{~g}\right) \\
\mathrm{TFC}\left(\mathrm{mg} \text { of } \mathrm{QE}^{3} / 100 \mathrm{~g}\right)\end{array}$ & $\begin{aligned} 1,610.3 & \pm 2.5^{4} \\
520.4 & \pm 1.8\end{aligned}$ & $\begin{aligned} 6.3 & \pm 0.2 \\
10.4 & \pm 0.1\end{aligned}$ & $\begin{array}{l}38.3 \pm 0.8^{* *} \\
23.6 \pm 0.1^{* *}\end{array}$ & $\begin{array}{l}8.1 \pm 0.9 \\
8.4 \pm 0.2\end{array}$ & $\begin{array}{l}41.1 \pm 0.9^{* *} \\
18.7 \pm 0.1^{* *}\end{array}$ \\
\hline
\end{tabular}

${ }^{1} \mathrm{R}=$ red ginseng extract; $\mathrm{M}=$ milk; $\mathrm{RM}=$ red ginseng + milk; $\mathrm{Y}=$ yogurt; $\mathrm{RY}=$ red ginseng + yogurt.

${ }^{2} \mathrm{GAE}=$ gallic acid equivalents.

${ }^{3} \mathrm{QE}=$ quercetin equivalents.

${ }^{4}$ All values are means $\pm \mathrm{SD}$.

** $P<0.01$ : significant difference between $\mathrm{M}$ and $\mathrm{RM}$ or between $\mathrm{Y}$ and $\mathrm{RY}$ based on Student's $t$-test.

Bacon and Rhodes, 1998; Kroll et al., 2000; de Freitas and Mateus, 2001; Rawel et al., 2001).

\section{Antioxidant Effect}

The $\mathrm{DPPH}^{\bullet}$ is a relatively stable organic radical and has been widely used to test the free radical scavenging ability of various samples. Results of DPPH radical scavenging ability of all the samples are presented in Table 2. All samples used in our study have shown direct DPPH RSA at a concentration range of 100 to $5,000 \mu \mathrm{g} / \mathrm{mL}$. It appeared that $\mathrm{M}, \mathrm{RM}, \mathrm{Y}$, and RY DPPH RSA ranged from $11.8 \pm 0.0$ to $14.6 \pm 1.7 \mu \mathrm{g} /$ $\mathrm{mL}, 15.1 \pm 0.5$ to $40.9 \pm 1.1 \mu \mathrm{g} / \mathrm{mL}, 5.8 \pm 0.5$ to $13.1 \pm 0.9 \mu \mathrm{g} / \mathrm{mL}$, and $18.7 \pm 1.1$ to $41.1 \pm 1.0 \mu \mathrm{g} /$ $\mathrm{mL}$, respectively. The results revealed that the RSA of dairy products supplemented with red ginseng were significantly higher $(P<0.01)$ than that of regular dairy products at all concentrations. Supplementation with red ginseng has been reported to yield high antioxidant activity (Kim et al., 2002). Similarly, it has been reported that herbal yogurts had higher antioxidant activity than plain yogurt (Amirdivani and Baba, 2011). It is likely that the presence of red ginseng influenced the dairy products with antioxidant activities.
The TRAP assay results for all the samples are presented in Table 3. The concentrations in samples ranged between 250 and $1,000 \mu \mathrm{g} / \mathrm{mL}$. The TRAP for $\mathrm{M}, \mathrm{RM}$, and RY ranged from $33.3 \pm 8.1$ to $308.1 \pm 6.4$ $\mu \mathrm{g} / \mathrm{mL}, 178.7 \pm 4.3$ to $903.5 \pm 6.7 \mu \mathrm{g} / \mathrm{mL}$, and 34.4 $\pm 8.7 \mu \mathrm{g}$ to $549.4 \pm 3.0 \mu \mathrm{g} / \mathrm{mL}$, respectively; however, it was not detected in $\mathrm{Y}$. This result indicates that the antioxidant effect of dairy products supplemented with red ginseng was greater than that of other dairy products at all concentrations.

The results for ORAC are summarized in the Figure 1. The DPPH RSA of M, RM, Y, and RY ranged from $1.9 \pm 0.1$ to $9.0 \pm 0.5 \mu \mathrm{g} / \mathrm{mL}, 7.7 \pm 0.4$ to $24.1 \pm 1.1$ $\mu \mathrm{g} / \mathrm{mL}, 2.0 \pm 0.2$ to $6.1 \pm 0.5 \mu \mathrm{g} / \mathrm{mL}$, and $8.1 \pm 0.4$ to $25.1 \pm 1.4 \mu \mathrm{g} / \mathrm{mL}$, respectively. As evidenced, ORAC of dairy products supplemented with red ginseng were significantly higher $(P<0.05)$ than other dairy products at all concentrations.

The cellular antioxidant capacity against $80 \mu M$ AAPH-induced oxidative stress in HepG2 cells (Figure 2) was evaluated at different concentrations (1, 5, 10, and $50 \mu \mathrm{g} / \mathrm{mL}$ ) of the extracts. All the samples tested significantly decreased AAPH-induced oxidative stress in HepG2 cells, and the addition of red ginseng to dairy products augmented the cellular antioxidant capacity at the highest concentration $(50 \mu \mathrm{g} / \mathrm{mL})$.

Table 2. The 1-diphenyl-2-picrylhydrazyl (DPPH) radical scavenging activity (means $\pm \mathrm{SD}, \mathrm{n}=3 ; \%$ ) of $\mathrm{M}$, $\mathrm{RM}, \mathrm{Y}$, and RY samples at different concentrations

\begin{tabular}{lccrc}
\hline & \multicolumn{4}{c}{ Sample $^{1}$} \\
\cline { 2 - 5 } $\begin{array}{l}\text { Concentration } \\
(\mu \mathrm{g} / \mathrm{mL})\end{array}$ & $\mathrm{M}$ & $\mathrm{RM}$ & $\mathrm{Y}$ & $\mathrm{RY}$ \\
\cline { 2 - 5 } 100 & $11.8 \pm 0.0^{\mathrm{NS}}$ & $15.1 \pm 0.5^{\mathrm{a} * *}$ & $5.8 \pm 0.5^{\mathrm{a}}$ & $18.7 \pm 1.1^{\mathrm{a} * *}$ \\
250 & $12.3 \pm 0.5$ & $15.5 \pm 0.8^{\mathrm{a} * *}$ & $10.1 \pm 0.3^{\mathrm{b}}$ & $19.3 \pm 0.7^{\mathrm{ab} * *}$ \\
500 & $12.4 \pm 1.0$ & $17.3 \pm 1.0^{\mathrm{a} * *}$ & $11.1 \pm 0.9^{\mathrm{b}}$ & $19.5 \pm 0.5^{\mathrm{ab} * *}$ \\
1,000 & $13.1 \pm 1.2$ & $21.2 \pm 1.5^{\mathrm{b} * *}$ & $10.1 \pm 0.9^{\mathrm{bc}}$ & $21.1 \pm 0.2^{\mathrm{b} * *}$ \\
2,500 & $14.1 \pm 1.0$ & $29.6 \pm 0.5^{\mathrm{c} * *}$ & $11.5 \pm 1.0^{\mathrm{bc}}$ & $31.2 \pm 1.2^{\mathrm{c} * *}$ \\
5,000 & $14.6 \pm 1.7$ & $40.9 \pm 1.1^{\mathrm{d} * *}$ & $13.1 \pm 0.9^{\mathrm{c}}$ & $41.1 \pm 1.0^{\mathrm{d} * *}$ \\
\hline
\end{tabular}

${ }^{\mathrm{a}-\mathrm{d}}$ Different superscripts within a column indicate significant difference with Tukey's post hoc test $(P<0.05)$. ${ }^{1} \mathrm{M}=$ milk; $\mathrm{RM}=$ red ginseng + milk; $\mathrm{Y}=$ yogurt; $\mathrm{RY}=$ red ginseng + yogurt.

${ }^{* *} P<0.01$ : significant difference between $\mathrm{M}$ and RM or between $\mathrm{Y}$ and RY at each concentration by Student's $t$-test. 
Table 3. Total antioxidant activity (means $\pm \mathrm{SD}, \mathrm{n}=3 ; \mathrm{m} M \mathrm{TEAC}^{1}$ ) of $\mathrm{M}, \mathrm{RM}, \mathrm{Y}$, and $\mathrm{RY}$ samples at different concentrations

\begin{tabular}{|c|c|c|c|c|}
\hline \multirow{2}{*}{$\begin{array}{l}\text { Concentration } \\
(\mu \mathrm{g} / \mathrm{mL})\end{array}$} & \multicolumn{4}{|c|}{ Sample $^{2}$} \\
\hline & M & $\mathrm{RM}$ & Y & RY \\
\hline $\begin{array}{l}250 \\
500 \\
750 \\
1,000\end{array}$ & $\begin{aligned} 33.3 & \pm 8.1^{\mathrm{a}} \\
124.9 & \pm 10.7^{\mathrm{b}} \\
152.9 & \pm 4.6^{\mathrm{c}} \\
308.1 & \pm 6.4^{\mathrm{d}}\end{aligned}$ & $\begin{array}{l}178.7 \pm 4.3^{\mathrm{a} * *} \\
503.0 \pm 9.2^{\mathrm{b} * *} \\
744.2 \pm 7.5^{\mathrm{c} * *} \\
903.5 \pm 6.7^{\mathrm{d} * *}\end{array}$ & $\mathrm{ND}^{3}$ & $\begin{array}{r}34.4 \pm 8.7^{\mathrm{a}} \\
287.5 \pm 6.8^{\mathrm{b}} \\
491.2 \pm 3.9^{\mathrm{c}} \\
549.4 \pm 3.0^{\mathrm{d}}\end{array}$ \\
\hline $\begin{array}{l}{ }^{\mathrm{a}-\mathrm{d}} \text { Different sup } \\
0.05) . \\
{ }^{1} \text { Trolox equival } \\
{ }^{2} \mathrm{M}=\text { milk; RM } \\
{ }^{3} \text { Not detected. }\end{array}$ & $\begin{array}{l}\text { fithin a column } \\
\text { dant capacity. } \\
\text { seng + milk; Y }\end{array}$ & $\begin{array}{l}\text { significant differ } \\
\text {; } \mathrm{RY}=\text { red ginse }\end{array}$ & $\begin{array}{l}\text { sed on } \\
\text { ogurt. }\end{array}$ & post hoc tes \\
\hline
\end{tabular}

It is well known that milk contains antioxidant compounds, such as naturally occurring $\beta$-carotene, vitamins (i.e., E and C), and enzymatic systems (Calligaris et al., 2004). Additionally, yogurt has been considered by nutritionists to have high nutritional value and positive bioactive effects (Lourens-Hattingh and Viljoen, 2001).

The higher free radical scavenging activity for Korean ginseng extract seen in our study may not only be due to ginsenosides, but also phenolic compounds such as maltol, salicylic acid, and vanillic acid, which have the activity to scavenge free radicals (Zhang et al., 1996; Kim et al., 2002). When a natural source of phenols was mixed with skim milk, a complex compound could be formed because the phenolic compounds would act as a polydentate ligand on the protein surface involving hydrogen bonding, as well as the presence of hydrophobic interactions enough to bind to milk protein. The type of this interaction depends on the type and the molar ratio of both phenolic compound and protein (Ricardo-
da-Silva et al., 1991; Prigent et al., 2003). Ginsenosides Rb1 and Rg1 in red ginseng have antioxidant activities on lipids (Kim et al., 2004). In addition, ginsenoside Rh2 can significantly increase antioxidant enzymatic activity, thus showing antioxidant effects (Kim et al., 1996; Lai et al., 2006). The potential of RSA of dairy products supplemented with red ginseng at all tested concentrations demonstrated a possible synergistic action.

\section{Antigenotoxic Effect}

The comet assay is a rapid and sensitive method for analyzing DNA damage at the level of individual cells; the introduction of lesion-specific enzymes, which induce strand breakage at the sites of oxidized bases, allows the measurement of endogenous oxidative DNA base damage (Collins et al., 1993, 1997).

The antigenotoxic effect against $\mathrm{H}_{2} \mathrm{O}_{2}$-induced DNA damage in leukocytes (Figure 3) was evaluated with

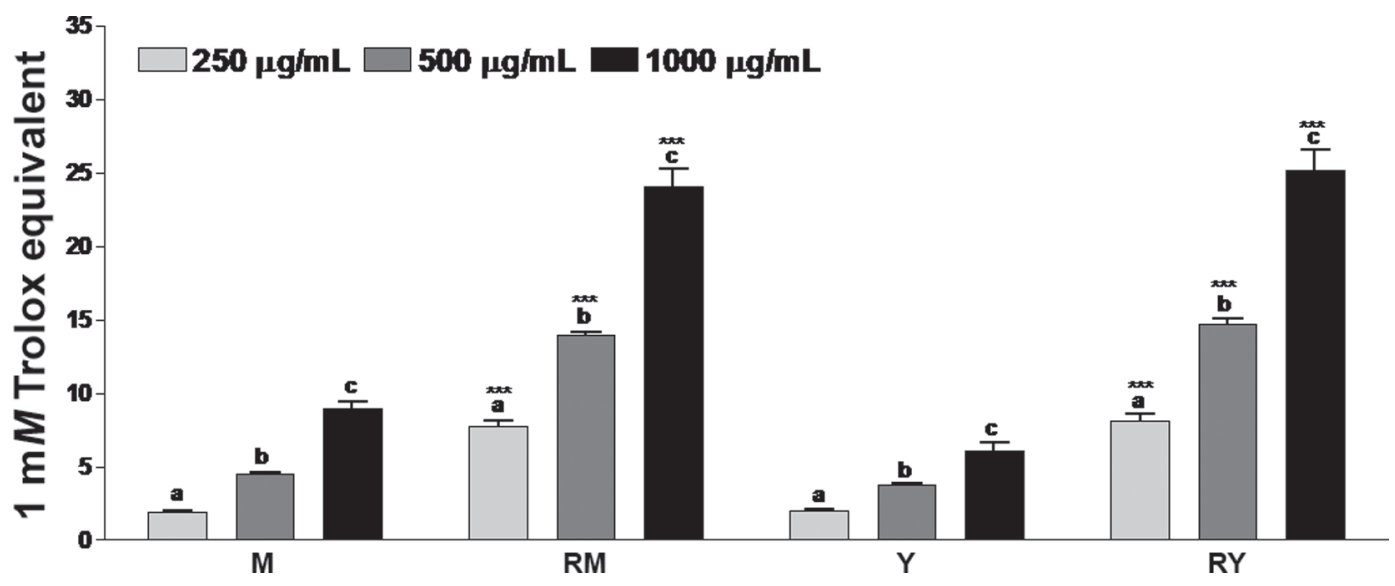

Figure 1. Oxygen radical absorbance capacity (ORAC) of milk (M), red ginseng and milk (RM), yogurt (Y), and red ginseng and yogurt (RY). The ORAC values expressed as Trolox equivalents $(\mathrm{m} M)$ according to different concentration of $\mathrm{M}, \mathrm{RM}, \mathrm{Y}$, and RY; means $\pm \mathrm{SD}(\mathrm{n}=$ $3)$. Values not sharing the same letter $(\mathrm{a}-\mathrm{c})$ are significantly different $(P<0.05)$ based on the Tukey's post hoc test. ${ }^{* * *} P<0.001$ : significant difference between M and RM and between Y and RY at each concentration based on Student's $t$-test. 


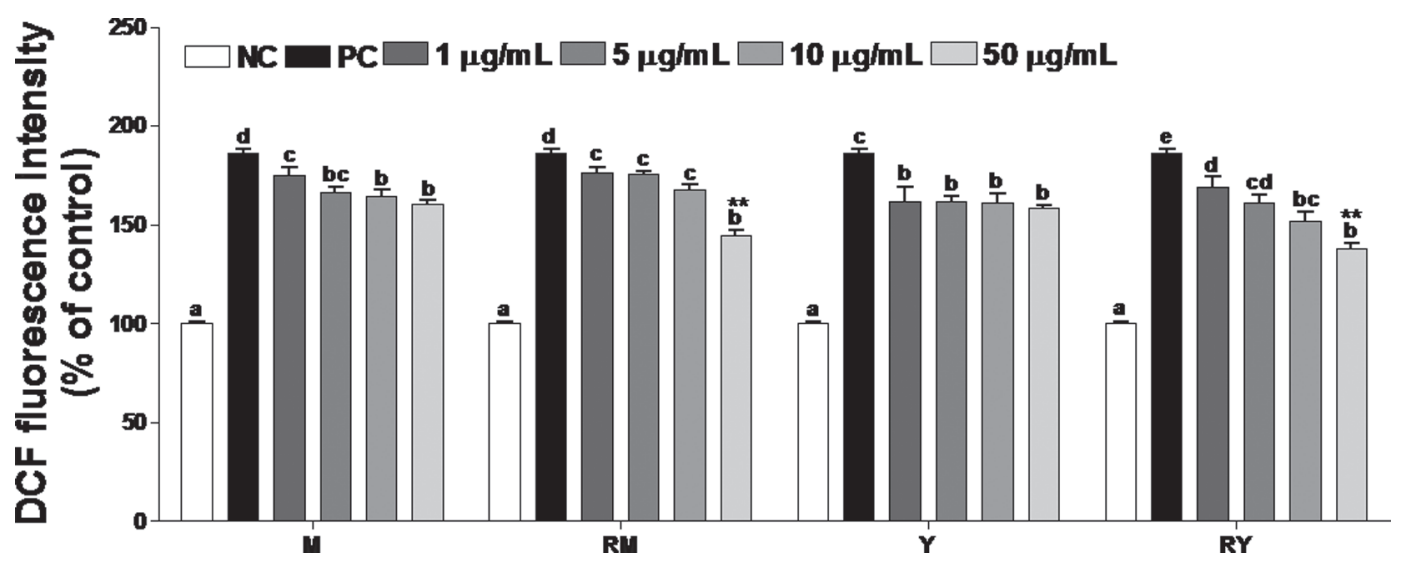

Figure 2. Cellular antioxidant capacity of milk (M), red ginseng and milk (RM), yogurt (Y), and red ginseng and yogurt (RY) extracts against $80 \mu M 2,2^{\prime}$-azobis (2-amidinopropane) dihydrochloride-induced oxidative stress in HepG2 cell mode. NC = negative control (without oxidative stimulus); $\mathrm{PC}=$ positive control; means $\pm \mathrm{SD}(\mathrm{n}=3) . \mathrm{DCF}=$ dichlorofluorescein. Values not sharing the same letter $(\mathrm{a}-\mathrm{d})$ are significantly different $(P<0.05)$ based on the Tukey's post hoc test. ${ }^{* *} P<0.01$ : significant difference between $\mathrm{M}$ and $\mathrm{RM}$ and between $\mathrm{Y}$ and RY at each concentration based on Student's $t$-test.

the extracts at different concentrations $(1,5,10$, and $50 \mu \mathrm{g} / \mathrm{mL}$ ). Our results showed that a protective effect against $\mathrm{H}_{2} \mathrm{O}_{2}$-induced DNA damage in human leukocytes was found in M, RM, and RY. Tail intensity of RY was significantly lower than that of $\mathrm{Y}$ at a concentration of $50 \mu \mathrm{g} / \mathrm{mL}$, whereas no additional protective effect was found.

Recent studies on the effectiveness of saponin components that are newly produced and converted in red ginseng fermentation (Trinh et al., 2007) have shown that 30 types of metabolic factors, including Rb1, Rb2, $\mathrm{Rc}$, and Rd, are converted to chemical components, such as compound $\mathrm{K}$, to enable endogenous absorption by intestinal microbial flora. In addition, the bioconverted saponin components have recently attracted increasing interest because of its intriguing biological actions. Previous research has demonstrated that compound $\mathrm{K}$ has antigenotoxic activity, which is mediated by these metabolites (Hasegawa and Uchiyama, 1998; Lee et al., 1998). Antigenotoxic effects may also be due to other components of fermented milks. For example, kefir contains water-soluble polysaccharides that have been shown to exert antitumor activity in vivo (LopitzOtsoa et al., 2006).

Some studies have shown the potential of lactobacilli and bifidobacteria to inhibit the genotoxic activity of chemical compounds (Pool-Zobel et al., 1996; Burns and Rowland, 2000; Tavan et al., 2002). Various lactobacilli occur in commercial dairy products such as yogurt, and it has been indicated that lactic acid bacteria may have shown antigenotoxic activity (Pool-Zobel et al., 1996; Lankaputhra and Shah, 1998).

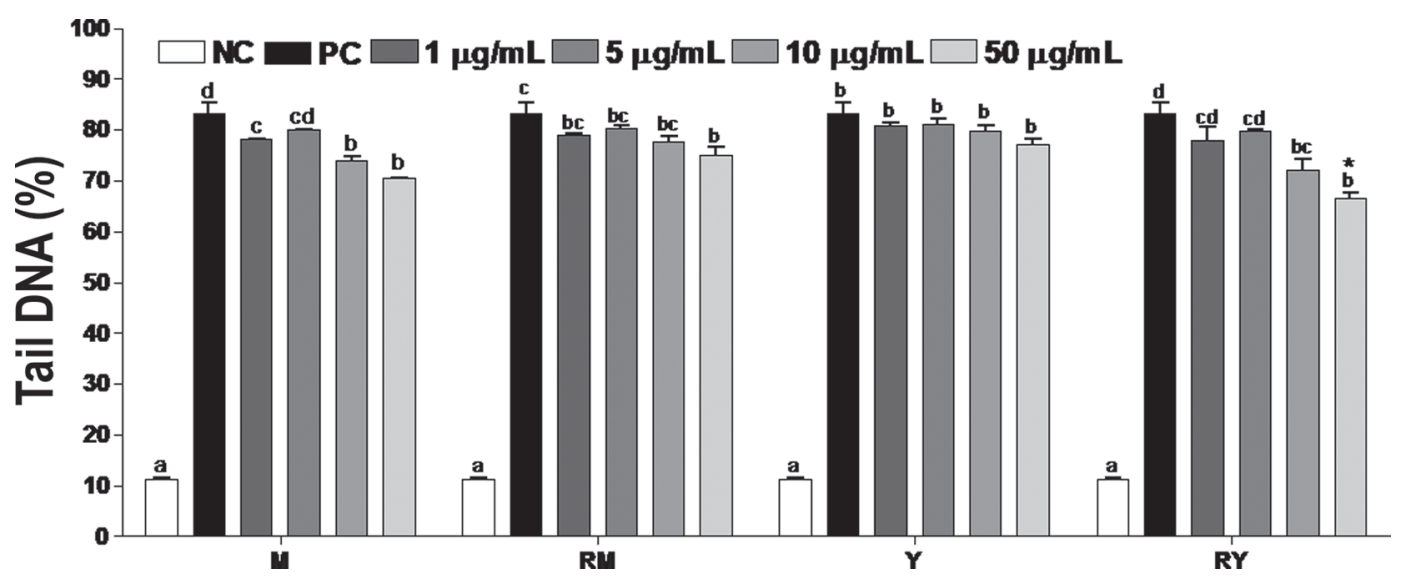

Figure 3. Antigenotoxic effect of milk (M), red ginseng and milk (RM), yogurt (Y), and red ginseng and yogurt $(\mathrm{RY})$ extracts. NC $=$ negative control; $\mathrm{PC}=200 \mu M \mathrm{H}_{2} \mathrm{O}_{2}$-treated positive control; means $\pm \mathrm{SE}(\mathrm{n}=4)$. Values not sharing the same letter $(\mathrm{a}-\mathrm{d})$ are significantly different $(P<0.05)$ based on Tukey's post hoc test. ${ }^{*} P<0.05$ : significant difference between Y and RY at each concentration based on Student's $t$-test. 


\section{CONCLUSIONS}

A positive correlation was observed between total phenolic and flavonoid content, antioxidant potential, and free RSA in dairy products supplemented with and without red ginseng. The present study specifically revealed the antioxidative (via DPPH, ORAC, TRAP, and CAC assays) and the antigenotoxic effect (via comet assay) of dairy products supplemented with red ginseng and showed that these capacities were similar in DPPH, ORAC, and TRAP assays. Based on these results, a recommendation can be made about dairy products to be enriched with red ginseng because of its high antioxidant activity. Thus, dairy products supplemented with red ginseng might be a promising natural source of antioxidants and could be used for the development of value-added products, such as functional dairy products.

\section{ACKNOWLEDGMENTS}

This research was supported by a grant (grant number: 610002-03-02-SB220) from the Technology Development Program for Agricultural and Forestry Ministry for Food, Agriculture and Fisheries, Sejong, Republic of Korea, and Priority Research Centers Program through the National Research Foundation of Korea (NFR) funded by the Ministry of Education, Science and Technology, Sejong, Republic of Korea (grant number: 2009-0093824).

\section{REFERENCES}

Abd El-Maksoud, A. A., I. H. Abd El-Ghany, H. S. El-Beltagi, S. Anankanbil, C. Banerjee, S. V. Petersen, B. Perez, and Z. Guo. 2018. Adding functionality to milk-based protein: Preparation, and physico-chemical characterization of beta-lactoglobulin-phenolic conjugates. Food Chem. 241:281-289.

Aloğlu, H. S., and Z. Öner. 2011. Determination of antioxidant activity of bioactive peptide fractions obtained from yogurt. J. Dairy Sci. 94:5305-5314.

Amirdivani, S., and A. S. Baba. 2011. Changes in yogurt fermentation characteristics, and antioxidant potential and in vitro inhibition of angiotensin-1 converting enzyme upon the inclusion of peppermint, dill and basil. Lebensm. Wiss. Technol. 44:1458-1464.

Bacon, J. R., and M. J. C. Rhodes. 1998. Development of a competition assay for the evaluation of the binding of human parotid salivary proteins to dietary complex phenols and tannins using a peroxidase-labeled tannin. J. Agric. Food Chem. 46:5083-5088.

Becker, E. M., L. R. Nielsen, and L. H. Skibsted. 2004. Antioxidant evaluation protocols: Food quality or health effects. Eur. Food Res. Technol. 219:561-567.

Boersma, B. J., R. P. Patel, M. Kirk, L. Patricia, D. Muccio, M. Victor, and S. Barnes. 1999. Chlorination and nitration of soy isoflavones. Arch. Biochem. Biophys. 368:265-275.

Burns, A. J., and I. R. Rowland. 2000. Anti-carcinogenity of probiotics and prebiotics. Curr. Issues Intest. Microbiol. 1:13-24.

Butler, G., J. H. Nielsen, T. Tina Slots, C. Chris Seal, M. D. Eyre, R. Sanderson, and C. Leifert. 2008. Fatty acid and fat-soluble antioxidant concentrations in milk from high- and low-input conven- tional and organic systems: seasonal variation. J. Sci. Food Agric. 88:1431-1441.

Calligaris, S., L. Manzocco, M. Anese, and M. C. Nicoli. 2004. Effect of heat-treatment on the antioxidant and pro-oxidant activity of milk. Int. Dairy J. 14:421-427.

Collins, A. R., V. L. Dobson, M. Dusinska, G. Kennedy, and R. Stetina. 1997. The comet assay: What can it really tell us? Mutat. Res. 375:183-193.

Collins, A. R., S. J. Duthie, and V. L. Dobson. 1993. Direct enzymic detection of endogenous oxidative base damage in human lymphocyte DNA. Carcinogenesis 14:1733-1735.

Coon, J. T., and E. Ernst. 2002. Panax ginseng: a systematic review of adverse effects and drug interactions. Drug Saf. 25:323-344.

Davis, D. W. 1947. Determination of flavonones in citrus juice. Anal. Chem. 19:46-48.

de Freitas, V., and N. Mateus. 2001. Structural features of procyanidin interactions with salivary proteins. J. Agric. Food Chem. 49:940-945.

Eom, S. J., J. E. Hwang, J. Jung, H.-S. Jee, K.-T. Kim, and H.-D. Paik. 2017a. Short communication: Antioxidative and antibacterial activities on Staphylococcus aureus and Escherichia coli O157:H4 in milk with added ginseng marc extract fermented by Lactobacillus plantarum KCCM 11613P. J. Dairy Sci. 100:7788-7792.

Eom, S. J., J. E. Hwang, K. T. Kim, and H. D. Paik. 2017b. Antibacterial effects against various foodborne pathogens and sensory properties of yogurt supplemented with Panax ginseng marc extract. Korean J. Food Sci. Anim. Resour. 37:787-791.

Folin, O., and W. Denis. 1912. On phosphotungstic-phosphomolybdic compounds as color reagents. J. Biol. Chem. 12:239-243.

Gad, A. S., and M. H. A. El-Salam. 2010. The antioxidant properties of skim milk supplemented with rosemary and green tea extracts in response to pasteurization, homogenization and the addition of salts. Int. J. Dairy Technol. 63:349-355.

Habtemariam, S., and A. Belai. 2018. Natural therapies of the inflammatory bowel disease: the case of rutin and its aglycone, quercetin. Mini Rev. Med. Chem. 18:234-243.

Hasegawa, H., and M. Uchiyama. 1998. Antimetastatic efficacy of orally administered ginsenoside Rb1 in dependence on intestinal bacterial hydrolyzing potential and significance of treatment with an active bacterial metabolite. Planta Med. 64:696-700.

Jiang, S. L., H. J. Liu, Z. C. Liu, N. Liu, R. Liu, Y. R. Kang, J. G. Ji, C. Zhang, B. J. Hua, and S. J. Kang. 2017. Adjuvant effects of fermented red ginseng extract on advanced non-small cell lung cancer patients treated with chemotherapy. Chin. J. Integr. Med. 23:331-337.

Joseph, N., A. Kumar, H. Singh, M. Shaheen, K. Das, and A. Shrivastava. 2018. Nutritional supplement and functional food use among medical students in India. J. Diet. Suppl. 15:951-964.

Jung, N. P., and S. H. Jin. 1996. Studies on the physiological and biochemical effects of Korean ginseng. J. Ginseng Res. 20:431-471.

Kawamoto, H., F. Nakatsubo, and K. Murakami. 1995. Quantitative determination of tannin and protein in the precipitates by highperformance liquid chromatography. Phytochemistry 40:15031505.

Kawamoto, H., F. Nakatsubo, and K. Murakami. 1996. Stoichiometric studies of tannin-protein co-precipitation. Phytochemistry 41:1427-1431.

Kim, D. J., K. S. Seong, D. W. Kim, S. R. Ko, and C. C. Chang. 2004. Antioxidative effects of red ginseng saponins on paraquat-induced oxidative stress. J. Ginseng Res. 28:5-10.

Kim, J. S., K. W. Kim, K. J. Choi, Y. K. Kwak, K. S. Im, K. H. Lee, and H. Y. Chung. 1996. Screening of antioxidative components from red ginseng saponin. Korean J. Ginseng Sci. 20:173-178.

Kim, Y. K., Q. Guo, and L. Packer. 2002. Free radical scavenging activity of red ginseng aqueous extracts. Toxicology 172:149-156.

Kroll, J., H. M. Rawel, and N. Seidelmann. 2000. Physicochemical properties and susceptibility to proteolytic digestion of myoglobinphenol derivatives. J. Agric. Food Chem. 48:1580-1587.

Lai, D. M., Y. K. Tu, I. M. Liu, P. F. Chen, and J. T. Cheng. 2006. Mediation of beta-endorphin by ginsenoside Rh2 to lower plas- 
ma glucose in sterptozotocin-induced diabetic rats. Planta Med. 72:9-13.

Lankaputhra, W. E. V., and N. P. Shah. 1998. Antimutagenic properties of probiotic bacteria and of organic acids. Mutat. Res. 397:169-182.

Lee, B. H., S. J. Lee, J. H. Hur, S. Lee, J. H. Sung, J. D. Huh, and C. K. Moon. 1998. In vitro antigenotoxic activity of novel ginseng saponin metabolites formed by intestinal bacteria. Planta Med. 64:500-503.

Li, J., H. Yu, S. Wang, W. Wang, Q. Chen, Y. Ma, Y. Zhang, and T. Wang. 2018. Natural products, an important resource for discovery of multitarget drugs and functional food for regulation of hepatic glucose metabolism. Drug Des. Devel. Ther. 12:121-135.

Liu, J. R., M. J. Chen, and C. W. Lin. 2005. Antimutagenic and antioxidant properties of milk kefir and soymilk-kefir. J. Agric. Food Chem. 53:2467-2474.

Liu, Z., J. Xia, C. Z. Wang, J. Q. Zhang, C. C. Ruan, and G. Z. Sun. 2016. Remarkable impact of acidic ginsenosides and organic acids on ginsenoside transformation from fresh ginseng to red ginseng. J. Agric. Food Chem. 64:5389-5399.

Lopitz-Otsoa, F., A. Rementeria, N. Elguezabal, and J. Garaizar. 2006. Kefir: a symbiotic yeasts-bacteria community with alleged healthy capabilities. Rev. Iberoam. Micol. 23:67-74.

Lorenz, M., N. Jochmann, A. Von Krosigk, P. Matris, G. Baumann, K. Stangl, and V. Stangl. 2007. Addition of milk prevents vascular protective effect of tea. Eur. Heart J. 28:219-223.

Lourens-Hattingh, A., and B. C. Viljoen. 2001. Yogurt as probiotic carrier food. Int. Dairy J. 11:1-17.

Mattila-Sandholm, T., and M. Saarela. 2005. Functional Dairy Products Book. Woodhead Ltd., Cambridge, UK, and CRC Press, Boca Raton, FL.

Pannala, A. S., C. A. Rice-Evans, B. Halliwell, and S. Singh. 1997. Inhibition of peroxynitrite-mediated tyrosine nitration by catechin polyphenols. Biochem. Biophys. Res. Commun. 232:164-168.
Pool-Zobel, B. L., R. C. Neudeke, I. Domizlaff, S. Ji, U. Schillinger, C. Rumney, M. Moretti, M. Villarini, G. Scassellati-Sforzolini, and I. Rowland. 1996. Lactobacillus- and Bifidobacterium-mediated antigenotoxicity in the colon of rats. Nutr. Cancer 26:365-380.

Prigent, S. V. E., H. Gruppen, A. J. W. G. Visser, G. A. van Koningsveld, G. A. H. de Jong, and A. G. J. Voragen. 2003. Effects of non-covalent interactions with 5-O-caffeoylquinic acid (chlorogenic acid) on the heat denaturation and solubility of globular proteins. J. Agric. Food Chem. 51:5088-5095.

Rawel, H. M., J. Kroll, and U. C. Hohl. 2001. Model studies on reactions of plant phenols with whey proteins. Nahrung 45:72-81.

Ricardo-da-Silva, J. M., V. Cheynier, J.-M. Souquet, M. Moutounet, J.-C. Cabanis, and M. Bourzeix. 1991. Interaction of grape seed procyanidins with various proteins in relation to wine fining. J. Sci. Food Agric. 57:111-125.

Rice-Evans, C., and N. J. Miller. 1994. Total antioxidant status in plasma and body fluids. Methods Enzymol. 234:279-293.

Songisepp, E., T. Kullisaar, P. Hütt, P. Elias, T. Brilene, M. Zilmer, and M. Mikelsaar. 2004. A new probiotic cheese with antioxidative and antimicrobial activity. J. Dairy Sci. 87:2017-2023.

Tavan, E., C. Cayuela, J. M. Antoine, and P. Cassand. 2002. Antimutagenic activities of various lactic acid bacteria against food mutagens: Heterocyclic amines. J. Dairy Res. 69:335-341.

Trinh, H. T., S. J. Han, S. W. Kim, Y. C. Lee, and D. H. Kim. 2007 Bifidus fermentation increases hypolipidemic and hypoglycemic effects of red ginseng. J. Microbiol. Biotechnol. 17:1127-1133.

Zhang, D., T. Yasuda, Y. Yu, P. Zheng, T. Kawabata, Y. Ma, and S. Okada. 1996. Ginseng extract scavenges hydroxyl radical and protects unsaturated fatty acids from decomposition caused by ironmediated lipid peroxidation. Free Radic. Biol. Med. 20:145-150. 